\title{
ANALISIS APPLICATION PROGRAMMING INTERFACE PADA MOBILE E-VOTING MENGGUNAKAN METODE TEST-DRIVEN DEVELOPMENT
}

\author{
Sunardi ${ }^{1}$, Imam Riadi ${ }^{2}$, Pradana Ananda Raharja ${ }^{3}$ \\ ${ }^{1}$ Program Studi Teknik Elektro, Universitas Ahmad Dahlan Yogyakarta \\ ${ }^{2}$ Program Studi Sistem Informasi, Universitas Ahmad Dahlan Yogyakarta \\ ${ }^{3}$ Program Studi Magister Teknik Informatika, Universitas Ahmad Dahlan Yogyakarta
}

\section{Informasi Makalah}

Dikirim, 8 April 2019

Direvisi, 20 September 2019

Diterima, Oktober 2019

\section{Kata Kunci:}

E-voting

Application Programming

Interface

Basis data

Test-Driven Development

Error

\begin{abstract}
INTISARI
Pengujian pada perangkat lunak dibutuhkan sebagai jaminan mutu terhadap kemampuan perangkat lunak. Perangkat lunak diterapkan pada pekerjaan yang nyata tanpa memiliki kendala terhadap kinerja dalam memberikan perintah, memproses perintah hingga memperoleh hasil dari pemrosesan sesuai dengan tujuan pengembangan. Pengujian unit Application Programming Interface (API) pada web service fokus sebagai upaya untuk menguji kemampuan pada tiap unit. Unit yang diuji secara spesifik akan digabungkan dengan unit lain hingga menjadi suatu sistem terintegrasi. Aplikasi mobile membutuhkan dukungan API sebagai penghubung dengan basis data, dimana aplikasi mobile dengan basis data tersebut tidak saling berhubungan secara langsung. Tampilan antarmuka pada aplikasi mobile hanya difokuskan sebagai interaksi visual antara pengguna dengan sistem. Sistem yang diberi perintah akan merespon dengan umpan balik yang dihubungkan melalui perantara dan merespon kembali melalui perantara dan dikembalikan dalam bentuk visual melalui antaramuka. Pengujian pada tiap unit sistem menggunakan proses Test-Driven Development (TDD) untuk menguji tiap fungsi. Perancangan dan pembangunan web service pada aplikasi $e$-voting memerlukan pengujian sehingga dalam penerapanya dapat digunakan sesuai dengan spesifikasi yang telah dirancanakan tanpa menimbulkan bug atau error yang dapat menganggu kinerja sistem. API yang telah diuji dan berinteraksi dengan antarmuka dapat melakukan proses data pemilih, validasi data pemilih dan pemilihan. Sistem ini juga telah diuji dengan metode System Usability Scale dengan skor total 69,02.
\end{abstract}

\section{Keyword:}

E-voting

Application Programming

Interface

Database

Test-Driven Development Errors

\begin{abstract}
Testing on the software is needed to guarantee its capabilities. So software in real condition wouldn't have any deflect with the performance to providing wich in line with the goal of development. Testing the Application Programming Interface (API) unit on the web service is an effort to testing the performance of each unit. Specifically tested unit will be combined with other units to become an integrated system. A Mobile application requires API support as the connector to a database, which not directly related to mobile application. The user-interface in mobile application only act as a visual interaction between the user and the system. The commanded system will respond through feedback which connected into a connector and gives the response back through the connector and returns in visual form through an interface. Test-Driven Development (TTD) was used in testing each system unit. Designing and building web service on e-voting application requires testing so that application can be used properly without causing bugs or errors that can interface system performance. Approved APIs are able to process voter data, validate voter data and election. The system also tested with "System Usability Scale" method which gains 69,02 total score.
\end{abstract}

\section{Korespondensi Penulis:}

Pradana Ananda Raharja 
Program Studi Teknik Informatika

Pascasarjana Universitas Ahmad Dahlan, Yogyakarta

JL. Prof. Dr. Soepomo, S.H., Janturan, Warungboto, Umbulharjo, Yogyakarta, 55164

Email: pradana1807048024@webmail.uad.ac.id / anandaprada@gmail.com

\section{PENDAHULUAN}

Voting adalah Suatu cara untuk memutuskan sesuatu dengan bantuan media, keputusan yang digunakan adalah keputusan dengan suara terbanyak. Media yang digunakan untuk mengumpulkan aspirasi dapat berupa media kertas yang saat ini digunakan. Hingga kini media voting yang masih digunakan memiliki kelemahan baik dalam prasyarat dan sarana. Data pemilih yang tidak sah, suara yang tidak sah serta proses voting itu masih belum efektif [1] [2]. Sistem e-voting yang telah dilindungi undang-undang dalam pemilihan umum dimasa mendatang terkait dengan keputusan Mahkamah Konstitusi yang menetapkan pasal 88 UU No. 32/2004 tentang Pemerintahan Daerah adalah Konstitusional selama $e$-voting menerapkan syarat Komulatif sebagai asas pemilu yang LUBERJURDIL dapat dilaksanakan [3].

Application Programming Interface (API) memiliki manfaat yang dimungkinkan pengembang dapat mengintegrasikan antara 2 bagian aplikasi atau aplikasi yang berbeda. Pengembangan aplikasi yang membutuhkan API yang terdiri dari beberapa element seperti function, protocols, dan tools. API digunakan untuk mempersingkat proses pengembangan sehingga pengembang tidak pelu membuat fitur yang sama. API adalah sebuah class yang dirancang untuk menghubungkan antara aplikasi mobile dengan basis data. Melalui class ini dapat berkeja untuk mengakses dan mengeksekusi beragam perintah dari aplikasi mobile [4] [5]. Web service sebagai komponen penghubung antara lapis antar muka dengan server yang mendukung prosedur dan fungsi-gungsi yang akan memproses perintah. Class yang ada pada web service memiliki peranan tersendiri sehingga tiap class tersebut diujikan kemampuannya dalam memproses perintah [6]. Aplikasi mobile merupakan sebuah teknologi yang memungkinkan dalam memenuhi kebutuhan informasi melalui perangkat dengan ukuran tertentu. Pada umumnya sistem operasi mobile yang digunakan saat ini adalah android dan iOS, android yaitu sistem operasi yang berbasis Linux sedangkan iOS adalah sistem operasi yang didistribusikan oleh Apple Inc. [7] [8] [9] [10].

Pengujian perangkat lunak bertujuan untuk menilai atau meningkatkan keandalan dalam menjamin mutu kerja perangkat sehingga terhindar dari kegagalan atau error yang tidak diinginkan. Tanpa pengujian dan jaminan mutu pada perangkat lunak yang rancang dan dibangun akan berakibat fatal dengan contoh kasus perangkat tersebut memiliki logic error, runtime error, dan syntax error. Pada error tersebut berakibat sistem yang dirancang tidak berjalan dengan semestinya. Sistem yang memiliki error atau bug berpengaruh terhadap kinerja seperti kesalahan pengisian data, kesalahan dalam pemrosesan, kesalahan pada hasil yang diharapkan. Maka perangkat lunak memerlukan pengujian yang mendetail pada unit yang tersedia sebelum unit-unit tersebut dihubungkan hingga menjadi sebuah sistem untuk dioperasikan [11] [12] [13]. Berdasarkan rancangan dan uji coba ditemukan kesalahan dalam request dan response pada aplikasi mobile ke database melalui API yang menyebabkan gangguan fatal, sehingga diperlukan uji coba pada fungsi yang tersedia pada API menggunakan metode TDD.

Techno Vol. 20, No. 2, Oktober 2019: 87 -94 


\section{METODE}

Metode $T D D$ pada pebelitian berikut digunakan sebagai pendekatan dalam menguji API. Metode $T D D$ yaitu suatu proses pengembangan perangkat lunak untuk menguji tiap unit pada sistem dengan siklus singkat [14]. Dalam menerapkan TDD terdapat hal yang harus dicermati yaitu mereplika suatu kondisi atau event disebut dengan Mocking. Proses yang terdapat pada pendekatan TDD antara lain, pertama menyiapkan beberapa rekayasa pengujian pada suatu komponen, membuat komponen tersebut hingga lulus uji, komponen

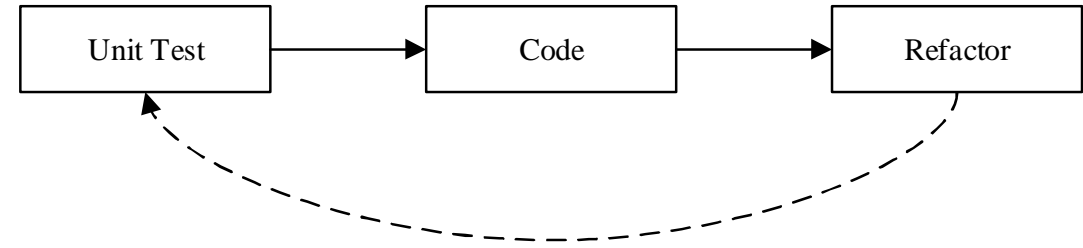

yang lulus uji disimpan dan diusun dengan komponen lainnya, dan Semua fitur, komponen serta source code yang telah lolos uji akan digabungkan secara lengkap dapat dilihat pada Gambar 1 [15]. TDD memiliki manfaat yang didapatkan yaitu apabila terdapat bug dan error dapat diketahui dengan tepat dan perbandingan dalam menguji seluruh sistem, pendekatan TTD memberikan waktu yang cepat dalam penggabungan sistem [16].

Gambar 1. Alur Kerja TDD [15]

\section{HASIL DAN PEMBAHASAN}

\subsection{Pengujian Unit}

Dalam pembuatan pengujian unit yang menggunakan tools PHPUnit sebagai aplikasi pengujian pada class, class berikut menjadi objek dalam pengujian pada class diterangkan pada Gambar 2.

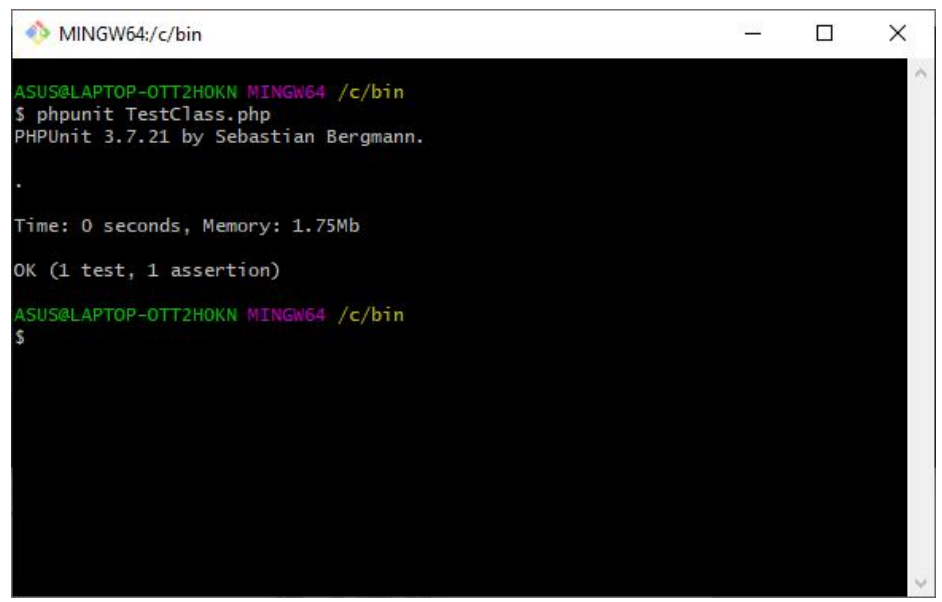

Gambar 2. Pengujian Class

Pada Gambar 2 merupakan unit yang diuji melalui link address menggunakan Postman, link address pada Gambar 2 digunakan untuk menguji proses yang diambil dari API untuk dibandingkan dengan data yang ada pada database. API mengambil data seperti data kandidat, data pemilih dan data administrasi untuk diproses.

\subsection{Implementasi Program}


Unit pengujian yang telah dibuat kemudian diimplementasika menjadi sebuah sistem, sistem yang di impementasikan terdiri dari 2 buah modul, modul pada Gambar 3 merupakan modul administrasi dan Gambar 4 adalah modul bilik suara. Pada modul ke 2 merupakan impementasi sistem administrasi $e$-voting dengan fitur utama yaitu pemrosesan data pemilih, validasi data pemilih, data kandidat dan hasil pemilihan. Menu pemrosesan data pemilih untuk melakukan input data pemilih yang sah sebagai pemilih, menu validasi pemilihan digunakan sebagai validasi pemilih sah yang hadir atau sebagai presensi pemilih yang akan melakukan pemilihan, data kandidat untuk melakukan proses data kandidat sebagai kandidat yang sah dalam proses pemilihan dan data tersebut terkoneksi ke modul bilik suara, kemudian menu hasil pemilihan adalah menu yang menampilkan persentase pemilih yang hadir selama pemilihan berlangsung dan hingga pemliihan telah ditutup maka akan secara otomatis menampilkan data pemilihan pada tiap kandidat. Pada menu ini pemilih yang telah melakukan pemilihan tidak dapat melakukan pemilihan lebih dari 1 kali dan data pemilih atas akndidit yang dipilih tidak terekam dalam database, akan tetapi hanya nilai kandidat yang dipilih akan bertambah. Pada Gambar 4 adalah implementasi dari modul bilik suara, pada menu tersebut peserta pemilihan yang sah yang hadir dan telah divalidasi maka pemilih dapat melakukan kegiatan pemilihan, pada modul bilik suara pemilih akan disajikan foto kandidat pemilihan. Kandidat yang dipilih oleh peserta pemilihan akan dikonfirmasi kebenaran data yang dipilih peserta pemilihan. Pada fitur konfirmasi tersebut dimaksudkan untuk meyakinkan pemilih apakah pemilih telah melakukan pemilihan sesuai prosedur.

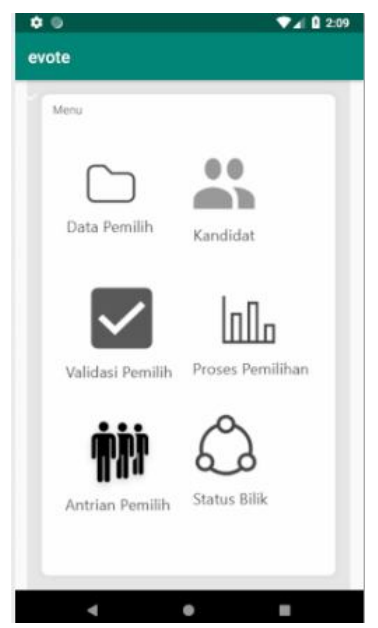

Gambar 3. Implementasi program modul administrasi

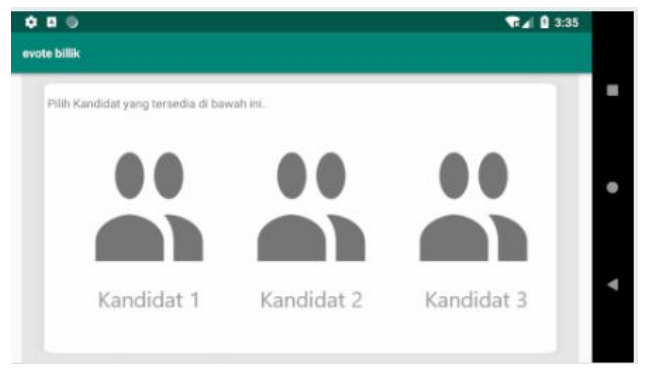

Gambar 4. Implementasi program modul bilik suara

\subsection{Hasil Pengujian}

Tahap yang dilakukan seletah melakukan tahap implementasi kode adalah tahapan pengujian menggunakan metoden $T T D$, hasil pegujian yang telah dilakukan dapat dilihat pada Gambar 6 sampai dengan Gambar 7. Pada Gambar 5 dalam class TestClass dalam baris kode 5 sampai dengan baris kode 12 berfungsi sebagai autentifikasi ke fitur administrasi yang mengacu pada file ceklogin.php.

\begin{tabular}{|c|c|}
\hline & $\begin{array}{l}\text { 1. <?php } \\
\text { 2. //Pengujian Autentifikasi } \\
\text { 3. class indexTest extends PHPUnit_Framework_TestCase } \\
\text { 4. }\{\quad \text { public function testFile() } \\
\text { 5. }\end{array}$ \\
\hline Techno Vol. 20, & $\begin{array}{ll}\text { 6. } & \text { ob_start (); } \\
\text { 7. } & \text { include 'ceklogin.php'; } \\
\text { 8. } & \text { \$content }=\text { ob_get_contents (); } \\
\text { 9. } & \text { ob_end_clean (); } \\
\text { 10. } & \text { \$this->assertEquals ('<a } \\
\text { 11. href="http://localhost/e_voting/index.php" }>\text { Index }</ a>\text { ', \$content); } \\
\begin{array}{l}\text { 12. } \\
\text { 13. }\end{array}\end{array}$ \\
\hline
\end{tabular}


Gambar 5. Implementasi kode yang akan diuji pada autentifikasi

Pada Gambar 6 merupakan hasil pengujian yang dijalankan, hasil pengujian gagal karena class yang dihubungkan sebagai autentifikasi tidak ditemukan ketika dilakukan pengujian. Sedangkan Gambar 7 hasil pengujian yang berhasil dilakukan sebagai autentifikasi pada fitur administrasi. Berdasarkan akun yang digunakan dapat melakukan login untuk mengakses fitur yang disediakan. Kemudian Tabel 1 menunjukan bahwa pengujian menggunakan metode TDD pada tiap unit telah berhasil dilakukan.

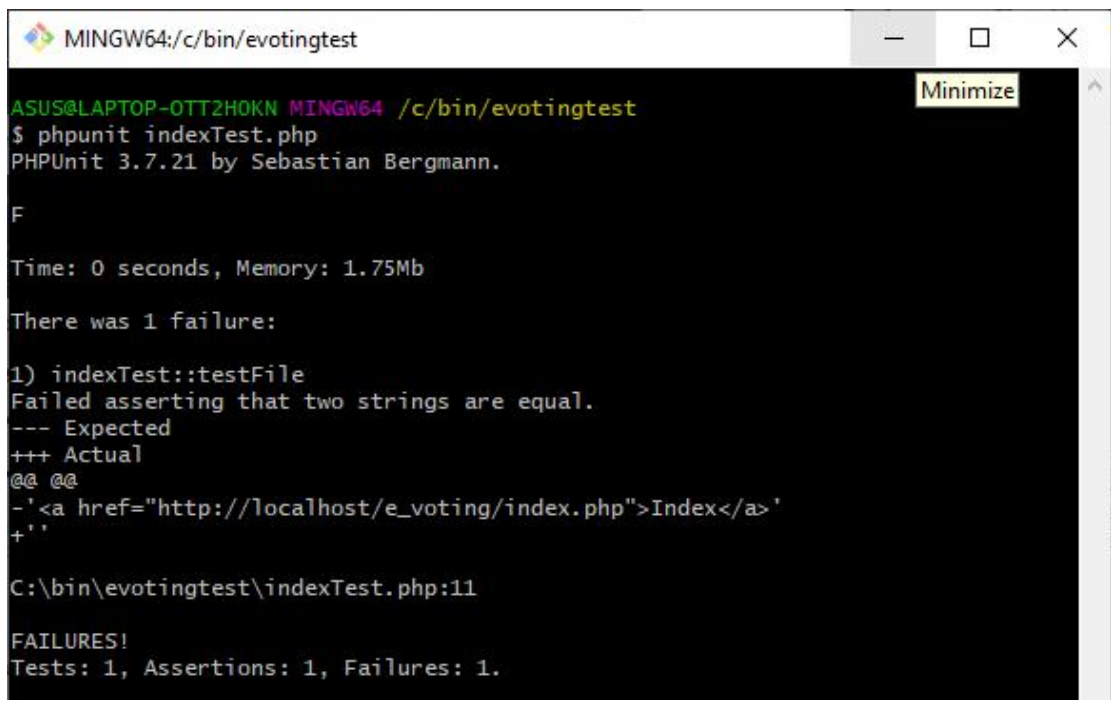

Gambar 6. Hasil pengujian gagal pada fitur administrasi

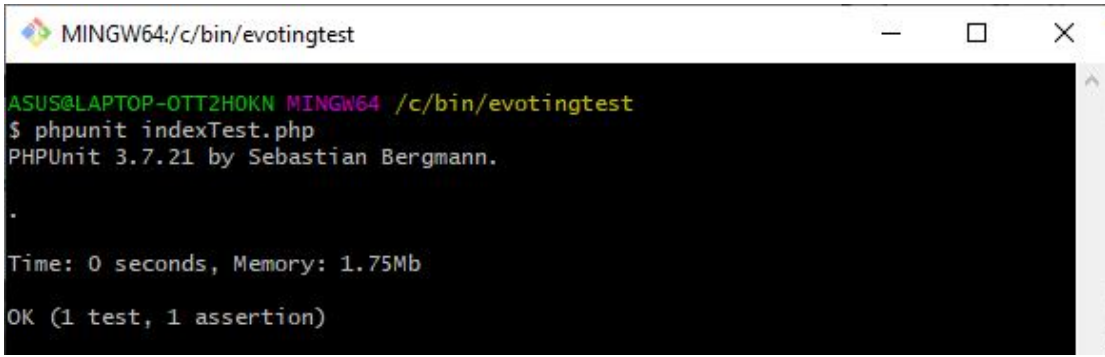

Gambar 7. Hasil pengujian berhasil pada fitur administrasi

Tabel 1. Hasil pengujian pada unit yang tersedia pada API

\begin{tabular}{cll}
\hline $\begin{array}{c}\text { Pengujian } \\
\text { Ke- }\end{array}$ & \multicolumn{1}{c}{ Unit } & Hasil Pengujian \\
\hline 1 & Login & Berhasil \\
2 & Data Pemilih & Berhasil \\
3 & Daftar Hadir & Berhasil \\
4 & Daftar Antrian & Berhasil \\
5 & Kandidat & Berhasil \\
6 & Proses Pemilihan & Berhasil \\
7 & Status Bilik & Berhasil \\
8 & Pemilihan & Berhasil \\
\hline
\end{tabular}

\subsection{Pengujian System Usability Scale}

Setelah melakukan implementasi dan pengujian maka selanjutnya dilakukan tahap pengujian System Usability Scale (SUS) dengan maksud untuk mengetahui pengalaman pengguna dalam menggunakan aplikasi 
yang telah dikembangkan [17] [18] [19] [20]. Terdapat 10 pernyataan dalam SUS yang diajukan ke pengguna yang telah melakukan uji coba mengoprasikan aplikasi, diantaranya sebagai berikut:

1. Saya merasa akan menggunakan sistem ini kembali.

2. Saya merasa sistem ini tidak rumit untuk digunakan.

3. Saya berfikir sistem ini mudah digunakan.

4. Saya merasa akan membutuhkan bantuan orang lain terkait penggunaan teknis sistem ini.

5. Saya melihat beragam fungsi pada sistem ini terintergrasi dengan baik.

6. Saya meilihat terdapat banyak ketidak konsistenan dalam sistem ini.

7. Saya berfikir bahwa orang lain akan cepat mempelajari penggunaan sistem ini.

8. Saya melihat bahwa sistem ini membingungkan.

9. Saya merasa bahwa tidak ada hambatan dalam menggunakan sistem ini.

10. Saya perlu mempelajari banyak hal dalam penggunaan sistem ini.

Berikut hasil dari pengambilan data yang diperoleh dari 36 responden yang sudah menyatakan pengalaman penggunaan sistem. Pernyataan dari Q1 - Q10 disajikan dalam rekapitulasi secara keseluruhan pada Tabel 2. Skala SUS dijelaskan pada Gambar 8 sebagai panduan skor SUS yang digunakan untuk kalibrasi skor. Didalam SUS Score terdapat 3 kategori yang berkaitan anatara lain Acceptability Ranges, Grade Scale, dan Adjective Ratings.

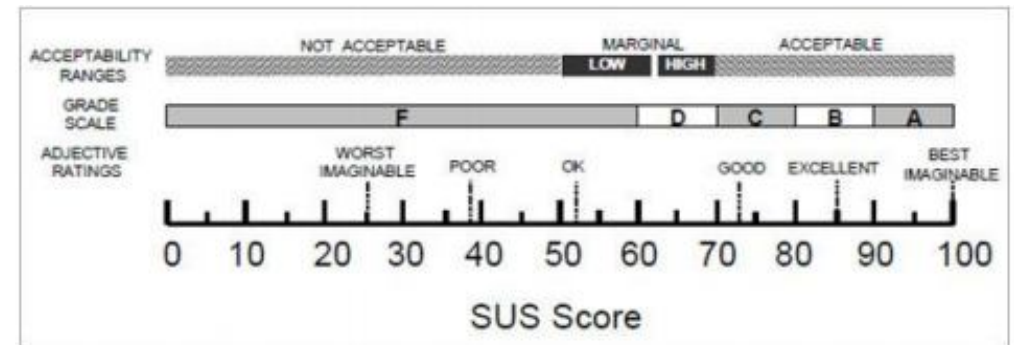

Gambar 8. Skor SUS

Tabel 2. Rekapitulasi Penyataan Responden

\begin{tabular}{|c|c|c|c|c|c|c|c|c|c|c|c|}
\hline Responden & & & & otal : & Pern & $\tan \mathrm{R}$ & nde & & & & \\
\hline & Q1 & Q2 & Q3 & Q4 & Q5 & Q6 & Q7 & Q8 & Q9 & Q10 & Total \\
\hline 1 & 3 & 3 & 4 & 2 & 3 & 2 & 4 & 1 & 3 & 3 & 70,0 \\
\hline 2 & 3 & 4 & 4 & 4 & 3 & 1 & 3 & 1 & 3 & 1 & 67,5 \\
\hline 3 & 3 & 4 & 2 & 2 & 4 & 3 & 3 & 3 & 3 & 2 & 72,5 \\
\hline 4 & 3 & 3 & 3 & 1 & 4 & 1 & 3 & 1 & 4 & 2 & 62,5 \\
\hline 5 & 2 & 3 & 3 & 3 & 4 & 3 & 2 & 2 & 3 & 2 & 67,5 \\
\hline 6 & 3 & 4 & 4 & 3 & 3 & 2 & 3 & 2 & 3 & 2 & 72,5 \\
\hline 7 & 3 & 4 & 4 & 3 & 4 & 2 & 3 & 2 & 2 & 2 & 72,5 \\
\hline 8 & 4 & 4 & 4 & 4 & 4 & 1 & 1 & 4 & 1 & 4 & 77,5 \\
\hline 9 & 2 & 4 & 3 & 2 & 4 & 2 & 2 & 2 & 3 & 2 & 65,0 \\
\hline 10 & 2 & 3 & 3 & 3 & 3 & 2 & 2 & 3 & 2 & 4 & 67,5 \\
\hline 11 & 3 & 3 & 4 & 3 & 3 & 2 & 2 & 2 & 3 & 4 & 72,5 \\
\hline 12 & 3 & 3 & 4 & 2 & 3 & 2 & 3 & 2 & 3 & 2 & 67,5 \\
\hline 13 & 3 & 3 & 3 & 1 & 3 & 2 & 3 & 1 & 3 & 3 & 62,5 \\
\hline 14 & 3 & 3 & 3 & 3 & 4 & 2 & 3 & 2 & 2 & 3 & 70,0 \\
\hline 15 & 3 & 3 & 3 & 2 & 3 & 2 & 3 & 3 & 2 & 3 & 67,5 \\
\hline 16 & 3 & 3 & 3 & 3 & 3 & 3 & 3 & 3 & 3 & 3 & 75,0 \\
\hline 17 & 2 & 4 & 3 & 1 & 3 & 4 & 2 & 2 & 3 & 1 & 62,5 \\
\hline 18 & 3 & 4 & 4 & 3 & 3 & 2 & 3 & 2 & 3 & 3 & 75,0 \\
\hline 19 & 2 & 3 & 2 & 2 & 2 & 2 & 3 & 2 & 2 & 4 & 60,0 \\
\hline 20 & 4 & 4 & 4 & 2 & 3 & 1 & 3 & 1 & 3 & 3 & 70,0 \\
\hline 21 & 3 & 3 & 3 & 4 & 4 & 1 & 2 & 2 & 3 & 3 & 70,0 \\
\hline 22 & 3 & 4 & 4 & 2 & 3 & 1 & 3 & 1 & 4 & 2 & 67,5 \\
\hline 23 & 4 & 3 & 3 & 4 & 3 & 2 & 3 & 2 & 2 & 3 & 72,5 \\
\hline 24 & 2 & 3 & 3 & 2 & 2 & 2 & 2 & 2 & 3 & 3 & 60,0 \\
\hline
\end{tabular}




\begin{tabular}{llllllllllll}
25 & 4 & 3 & 3 & 4 & 4 & 3 & 4 & 2 & 3 & 4 & 85,0 \\
26 & 4 & 3 & 3 & 2 & 4 & 1 & 3 & 1 & 3 & 2 & 65,0 \\
27 & 4 & 3 & 4 & 2 & 3 & 2 & 3 & 1 & 4 & 2 & 70,0 \\
28 & 3 & 4 & 3 & 1 & 3 & 1 & 4 & 1 & 3 & 3 & 65,0 \\
29 & 3 & 3 & 3 & 2 & 3 & 2 & 3 & 2 & 3 & 2 & 65,0 \\
30 & 3 & 4 & 4 & 1 & 4 & 1 & 1 & 1 & 4 & 4 & 67,5 \\
31 & 3 & 4 & 4 & 1 & 3 & 1 & 3 & 1 & 4 & 2 & 65,0 \\
32 & 3 & 4 & 4 & 2 & 3 & 3 & 4 & 2 & 4 & 3 & 80,0 \\
33 & 3 & 4 & 4 & 2 & 4 & 2 & 2 & 2 & 3 & 2 & 70,0 \\
34 & 3 & 4 & 4 & 3 & 4 & 2 & 4 & 1 & 3 & 3 & 77,5 \\
35 & 4 & 4 & 0 & 1 & 3 & 1 & 2 & 2 & 2 & 3 & 55,0 \\
36 & 3 & 4 & 4 & 3 & 3 & 3 & 2 & 1 & 2 & 4 & 72,5 \\
\hline
\end{tabular}

Berkaitan dengan hasil data dari responden yang kemudian diolah dalam Tabel 2 maka dapat disimpulkan bahwa skor SUS dapat dijumlahkan berdasarkan dari skor total 2485,0 dengan jumlah reponden sebanyak 36 orang kemudian dibagi jumlah reponden itu sendiri dengan rata-rata skor 69,02.

\section{KESIMPULAN}

Berkaitan dengan hasil pembahasan, telah diuji class pada API untuk aplikasi $e$-voting pemilihan kepala daerah dengan metode Test-Driven Development untuk melakukan proses data pemilh, validasi data pemilih dan pemilihan. Hasil pengujian tersebut menunjukan dapat dintegrasikan antar class menjadi sebuah API dengan aplikasi mobile. Berdasarkan hasil yang diperoeh dari pengujian yang dilandasi dari pengalaman pengguna dalam menggunakan sistem menggunakan pengujian System Usability Scale dapat disimpulkan skor yang diperoleh adalah 69,02 sehingga dapat diketahui bahwa sistem dapat diterima oleh pengguna dengan tingkat kategori Adjective Ratings yang 'Ok' dan juga dapat diketahui bahwa Acceptability Ranges dalam rentang Marginal 'High'.

\section{DAFTAR PUSTAKA}

[1] P. A. Raharja, Sunardi and I. Riadi, "Perancangan E-voting Berbasis Mobile Menggunakan Metode Test-Driven Development," in Seminar Nasional PPM UNESA 2018, Surabaya, 2018.

[2] A. Yudhana, R. Umar and F. Alameka, "Perancangan Sistem Informasi Menggunakan Enterprise Architecture Planning (Studi Kasus Pada Kecamatan di Kota Samarinda)," Jurnal Ilmu Komputer dan Informatika, vol. 4, pp. 114-123, 2018.

[3] E. Priyono and F. N. Dihan, "E-voting: Urgensi Transparansi dan Akuntabilitas," in Seminar Nasional Informatika 2010, Yogyakarta, 2010.

[4] Z. Musliyana, "Sistem Pendaftaran Hostspot Berbasis Web Pada Hotspot Mikrotik STIMIK U'budiyah Menggunakan Mikrotik Application Programming Interface (API), PHP dan MySQL," in Prosiding SNIKOM 2014, Banda Aceh, 2014.

[5] A. Yudhana, Sunardi and A. Ikrom, "APLIKASI ANDROID UNTUK MONITORING KUALITAS LAHAN PERTANIAN," in Prosiding SNST, Semarang, 2018.

[6] R. Hidayat and A. Ashari, "Penerapan Teknologi Web Service Untuk Integrasi Layanan Puskesmas dan Rumah Sakit," Journal of Mathematics and Natural Sciences, vol. 23, 2013.

[7] J. Hendrawan, "Rancang Bangun Aplikasi Mobile Learning Untuk Tuntunan Shalat," Journal of Information Technology and Computer Science (INTECOMS), vol. 1, pp. 44-59, 2018.

[8] E. Prianto, A. Yudhana and A. Fadlil, "Analisis Perancangan Aplikasi Administrasi Kepegawaian dan Kegiatan Berbasis Android," in Prosiding Seminar Nasional Multi Disiplin Ilmu \& Call For Papers, 2017.

[9] F. Liu, K.-S. Liu, C. Chang and Y. Wang, "Research on the technology of iOS jailbreak," 2016 Sixth International Conference on Instrumentation \& Measurement, Computer, Communication and Control, pp. 644-647, 2016.

[10] A. Yudhana, Sunardi and I. A. Mukaromah, "Implementation of Winnowing Algorithm with Dictionary 
English-Indonesia Technique to Detect Plagiarism," International Journal of Advanced Computer Science and Applications, vol. 9, pp. 183-189, 2018.

[11] A. Yudhana, S. and A. J. S. Hartanta, "Perancangan Aplikasi Smartphone Android Untuk Penentuan Pola Satu Sisi Penggergajian Kayu Sengon," in Prosiding SNST 2018, 2018.

[12] D. Contoneo, R. Pietrantiono and S. Russo, "Relai Testing: a technique to assess and improve software reliability," IEEE Transactions on Software Engineering, vol. 24, pp. 1-23, 2015.

[13] A. Basir, A. Fadlil and I. Riadi, "Enterprise Architecture Planning Sistem Informasi Akademik Dengan TOGAF ADM," Jurnal Sains Komputer \& Informatika (J-SAKTI), vol. 3, pp. 1-10, 2019.

[14] J. H. Yuliansyah and I. Riadi, "Impemetasi Test Driven Development Pada Pengembangan Aplikasi Android Untuk Mahasiwa Universitas Ahmad Dahlan," Jurnal Ilmu Teknik Elektro dan Informatika (JITEKI), vol. 4, pp. 43-50, Juni 2018.

[15] A. N. A. Thohari and A. E. Amalia, "Jurnal Sistem Informasi dan Teknologi," Implementasi Test Driven Development Dalam Pengembangan Aplikasi Berbasis Web, vol. 1, pp. 1-10, 2018.

[16] Dimas, "TDD (Test Driven Development)," 16 Maret 2018. [Online]. Available: https://sis.binus.ac.id/2018/03/16/tdd-test-driven-development/. [Accessed 7 Maret 2019].

[17] Z. Sharfina and H. B. Santoso, "An Indonesian Adaptation of the System Usability," in International Conference on Advanced Computer Science and Information Systems (ICACSIS) , 2016.

[18] J. Brooke, "SUS: A Retrospective," Journal of Usability Studies, vol. 8, pp. 29-40, 2013.

[19] C. Katsanos, N. Tselios and M. Xenos, "Perceived Usability Evaluation of Learning Management Systems: A First Step," in Panhellenic Conference on Informatics, 2012.

[20] Rosmiati, I. Riadi and Y. Prayudi, "A Maturity Level Framework for Measurement of Information Security Performance," International Journal of Computer Applications, vol. 141, pp. 1-6, 2016. 